University of Nebraska - Lincoln

DigitalCommons@University of Nebraska - Lincoln

2-13-2006

\title{
Landsat cross-calibration based on near simultaneous imaging of common ground targets
}

P.M. Teillet

Canada Centre for Remote Sensing, phil.teillet@nrcan.gc.ca

B. L. Markham

NASA's Goddard Space Flight Center, brian.I.markham@nasa.gov

Richard R. Irish

Science Systems and Applications, Inc.

Follow this and additional works at: https://digitalcommons.unl.edu/nasapub

Part of the Physical Sciences and Mathematics Commons

Teillet, P.M.; Markham, B. L.; and Irish, Richard R., "Landsat cross-calibration based on near simultaneous imaging of common ground targets" (2006). NASA Publications. 14.

https://digitalcommons.unl.edu/nasapub/14

This Article is brought to you for free and open access by the National Aeronautics and Space Administration at DigitalCommons@University of Nebraska - Lincoln. It has been accepted for inclusion in NASA Publications by an authorized administrator of DigitalCommons@University of Nebraska - Lincoln. 


\title{
Landsat cross-calibration based on near simultaneous imaging of common ground targets
}

\author{
P.M. Teillet ${ }^{\mathrm{a}, *}$, B.L. Markham ${ }^{\mathrm{b}}$, Richard R. Irish ${ }^{\mathrm{c}}$

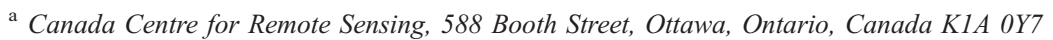 \\ ${ }^{\mathrm{b}}$ NASA's Goddard Space Flight Center, Code 923, Greenbelt, Maryland 20771, USA \\ ${ }^{c}$ Science Systems and Applications, Inc., 5900 Princess Garden Parkway, Lanham, Maryland 20706, USA
}

Received 14 November 2005; received in revised form 13 February 2006; accepted 13 February 2006

\begin{abstract}
The paper presents the results of an extended analysis of image data sets acquired during the tandem-orbit configuration in 1999 for the purposes of radiometric cross-calibration of the Landsat-7 Enhanced Thematic Mapper Plus (ETM+) and Landsat-5 Thematic Mapper (TM) sensors. Earlier work focused on the tandem pair for the Railroad Valley Playa, Nevada (RVPN) site to tie down the Landsat-5 TM calibration based on the more accurate Landsat-7 ETM+ calibration. This paper describes new results based on as many as eight tandem image pairs. The additional tandem images are of primarily vegetated areas for which little or no ground reference data were available. Increasing the number of tandem pairs yielded results for the Landsat $5 \mathrm{TM}$ gain coefficients within approximately $\pm 1 \%$ of the RVPN-based results in spectral bands $1,2,3$ and 7 , and within $-2 \%$ and $-4 \%$ of the RVPN-based results for spectral bands 4 and 5 , respectively.
\end{abstract}

Crown Copyright (C) 2006 Published by Elsevier Inc. All rights reserved.

Keywords: Landsat; Radiometric calibration; Vicarious calibration

\section{Introduction}

Earth surfaces with suitable characteristics have long been used to verify the post-launch radiometric calibration performance of satellite sensors. Any associated field measurement campaigns are resource intensive activities and so it is of considerable interest to develop less expensive complementary approaches that can provide more frequent calibration updates, even if they are less accurate. Hence, the use of test sites to check the radiometric calibration of a given satellite sensor without coincident surface measurements or to transfer radiometric calibration between satellite sensors (so-called crosscalibration) without coincident surface measurements has been on the increase.

\footnotetext{
* Corresponding author.

E-mail address: phil.teillet@nrcan.gc.ca (P.M. Teillet).
}

This paper explores aspects of the radiometric crosscalibration of the Landsat-7 Enhanced Thematic Mapper Plus (ETM+) and Landsat-5 Thematic Mapper (TM) sensors based on near-simultaneous imaging of common ground targets facilitated by a tandem-orbit configuration. The launch of Landsat-7 on April 15, 1999 placed the spacecraft temporarily in an orbit with a ground track very close to that of the Landsat-5 spacecraft. The key period for this tandem configuration was June 1-4, 1999 when the orbital tracks were almost exactly the same, with a temporal offset on the order of 10 to $30 \mathrm{~min}$. This unusual and valuable opportunity was designed to facilitate the establishment of data consistency between Landsat-7 and Landsat-5. During the tandem configuration period when there was useful overlap in coverage between the two sensors, image sequences corresponding to numerous matching scenes were recorded by both the Landsat-7 ETM+ and, in cooperation with Space Imaging EOSAT and international ground stations, the Landsat-5 TM. Subsequently, the Landsat-7 orbit was raised to $705 \mathrm{~km}$ for nominal operations. Teillet et al. (2001a, 2004a) focused on the tandem pair for the Railroad Valley Playa, 
Nevada (RVPN) site to tie down the Landsat-5 TM radiometric calibration with respect to the more accurate Landsat-7 ETM+ calibration. ${ }^{1}$ The uncertainty for the calibration transfer method was estimated to be $\pm 3.5 \%$ in the absence of spectral band difference effects (Teillet et al., 2001a).

This short communication describes additional results based on eight tandem image pairs and examines aspects of the common ground-look cross-calibration methodology in greater detail. Although Teillet et al. (2001a) recommended that vegetated surfaces should not be used for cross-calibration, it was deemed worthwhile to check the possibility that the combined use of many tandem image pairs of such surface targets has the potential to yield helpful results for monitoring sensor performance between resource-intensive calibration campaigns.

\section{Satellite sensor cross-calibration based on common ground looks}

Cross-calibration is one of the various methods used for postlaunch satellite sensor calibration. Here, a given sensor is calibrated against another satellite sensor for which the radiometric calibration is better known via near-simultaneous imaging of a common ground target (Teillet et al., 1990). Much of the cross-calibration work over the years has been undertaken because of the significant calibration drift and lack of onboard calibration for the shortwave bands of the NOAA Advanced Very High Resolution Radiometers, a series of sensors that have played an important role in global environmental monitoring. Teillet et al. (1990) used large flat areas at White Sands, New Mexico to update the calibration of the NOAA-9 and NOAA-10 AVHRRs based on Landsat-5 TM and SPOT High Resolution Visible (HRV) image data acquired the same day. Teillet et al. (2001b) generalized the methodology and demonstrated it for multiple sensors over multiple test sites, taking directional reflectance effects and spectral band differences into account.

Cabot et al. (2000) used desert sites in Africa to crosscalibrate sensors such as AVHRR, SeaStar Sea-viewing Wide Field-of-view Sensor (SeaWiFS), and SPOT-4 Vegetation (VGT) with respect to the Polarization and Directionality of the Earth's Reflectances (POLDER) sensor. O'Brien and Mitchell (2001) examined the calibration of AVHRR with respect to the well-calibrated Along Track Scanning Radiometer (ATSR-2) on the European Remote Sensing ERS-2 satellite by comparing reflectances over a bright target in a semi-arid environment. Trishchenko et al. (2002) focused on moderate resolution satellite sensors, including the AVHRRs onboard the NOAA- $6,-7,-8,-10,-11,-12,-14,-15,-16$ spacecraft, Terra Moderate-resolution Imaging Spectroradiometer (MODIS), VGT, and Global Imager (GLI) on the second Advanced Earth Observing Satellite (ADEOS-2), all with respect to NOAA-9 AVHRR. Rao et al. (2003) presented results on the

\footnotetext{
${ }^{1}$ Teillet et al. (2001a) also examined a tandem image pair for the Niobrara grassland site, since ground reference data were available. However, the radiometric cross-calibration between Landsat-5 TM and Landsat-7 ETM+ was based on the RVPN tandem pair only, because the Niobrara grassland is less well understood as a calibration site and the RVPN site is one of the most extensively characterized and used optical calibration test sites in the world.
}

inter-calibration of Terra MODIS and the ERS-2 ATSR-2 based on desert sites as common targets. Thome et al. (2003) used RVPN to cross-calibrate Earth Observing-1 (EO-1) Advanced Land Imager (ALI), EO-1 Hyperion, MODIS, and Ikonos with respect to $\mathrm{ETM}+$.

\section{Methodology}

\subsection{Landsat tandem image pairs selected for analysis}

Table 1 provides information about the eight Landsat tandem image pairs utilized in the study and defines the abbreviations used henceforth to identify the sites. Despite there being hundreds of Landsat tandem image pairs, it proved difficult to find large, reasonably homogeneous areas that were also unaffected by clouds and so only eight pairs were selected. Four of the sites are illustrated in Fig. 1. All sixteen images involved were acquired 1-3 June 1999 during the aforementioned Landsat tandem configuration period. The RVPN tandem pair served as the reference case because it was used for the cross-calibration of Landsat-5 and Landsat-7 sensors. Surface reflectance spectra were only available on image acquisition days for the RVPN and NIOB cases. No ground reference data were available the other six tandem image pairs.

\subsection{Radiometric formulation}

The key radiometric equations for top-of-atmosphere (TOA) at-sensor quantities are as follows (Teillet et al., 2001a). For a given spectral band $i$ :

Raw image quantized level (in counts) $=Q_{i}=G_{i} L_{i}^{*}+Q_{0 i}$,

At-sensor radiance (inWatts $/\left(\mathrm{m}^{2}\right.$ sr $\left.\mu m\right)$ )

$$
=L_{i}^{*}=\left(Q_{i}-Q_{0 i}\right) / G_{i}=\Delta Q_{i} / G_{i},
$$

At-sensor reflectance $=\rho_{i}^{*}=\pi L_{i}^{*} d_{\mathrm{s}}^{2} /\left(E_{0 i} \cos \theta\right)$.

In these equations, $G_{i}$ is band-averaged sensor responsivity (in counts per unit radiance) and $Q_{0 i}$ is the band-averaged zeroradiance bias (in counts) in spectral band $i$. Also, $E_{0 i}$ is the exoatmospheric solar irradiance (in Watts/ $\left(\mathrm{m}^{2} \mu \mathrm{m}\right)$ ), $\theta$ is the solar zenith angle, and $d_{\mathrm{s}}$ is the Earth-Sun distance in Astronomical Units. Bias-corrected image values are then given by

$\Delta Q_{i}=Q_{i}-Q_{0 i}=G_{i} \rho_{i}^{*} E_{0 i} \cos \theta /\left(\pi d_{\mathrm{s}}^{2}\right)$.

Eq. (4) can be defined separately for image data from the reference sensor Landsat-7 ETM+ ("L7") and for image data from the other sensor Landsat-5 TM ("L5"), whose calibration is to be obtained via cross-calibration with respect to sensor L7 in analogous spectral band $i$. After algebraic manipulation, this leads to a formula for cross-calibration between image data from L7 and adjusted image data from L5:

$\Delta Q_{i \mathrm{~L} 5 A}=A_{i} \Delta Q_{i \mathrm{~L} 5}=\left(G_{i \mathrm{~L} 5} / G_{i \mathrm{~L} 7}\right) \Delta Q_{i \mathrm{~L} 7}=M_{i} \Delta Q_{i \mathrm{~L} 7}$,

where the factor $A_{i}$ adjusts L5 radiances for illumination and spectral band difference effects and $M_{i}$ is the slope of the linear 
Table 1

Information about the tandem image pairs used in this study

\begin{tabular}{|c|c|c|c|c|}
\hline Pair \# & Location & Abbreviation & $\begin{array}{l}\text { WRS-2 path/row } \\
\text { latitude, longitude }\end{array}$ & $\begin{array}{l}\text { Cell sizes for L7 } \\
\text { Cell sizes for L5 }\end{array}$ \\
\hline 1 & $\begin{array}{l}\text { Niobrara } \\
\text { grassland, } \\
\text { Nebraska }\end{array}$ & NIOB & $\begin{array}{l}31 / 30 \\
+42^{\mathrm{d}} 48^{\mathrm{m}},-100^{\mathrm{d}} 01^{\mathrm{m}}\end{array}$ & $\begin{array}{l}704 \text { by } 438 \\
696 \text { by } 434\end{array}$ \\
\hline 2 & $\begin{array}{l}\text { Washington, } \\
\text { DC area }\end{array}$ & WDCA & $\begin{array}{l}15 / 33 \\
+39^{\mathrm{d}},-77^{\mathrm{d}}\end{array}$ & $\begin{array}{l}273 \text { by } 153 \\
271 \text { by } 152\end{array}$ \\
\hline 3 & $\begin{array}{l}\text { Eastern shore, } \\
\text { Lake Michigan }\end{array}$ & ESLM & $\begin{array}{l}22 / 31 \\
+41^{\mathrm{d}} 46^{\mathrm{m}},-86^{\mathrm{d}} 47^{\mathrm{m}}\end{array}$ & $\begin{array}{l}454 \text { by } 362 \\
445 \text { by } 358\end{array}$ \\
\hline 4 & $\begin{array}{l}\text { Botswana } \\
\text { vegetation }\end{array}$ & BOTS & $\begin{array}{l}175 / 74 \\
-20^{\mathrm{d}} 14^{\mathrm{m}},+22^{\mathrm{d}} 27^{\mathrm{m}}\end{array}$ & $\begin{array}{l}934 \text { by } 852 \\
930 \text { by } 843\end{array}$ \\
\hline 5 & $\begin{array}{l}\text { Australia } \\
\text { vegetation }\end{array}$ & AUST & $\begin{array}{l}111 / 74 \\
-20^{\mathrm{d}},+122^{\mathrm{d}}\end{array}$ & $\begin{array}{l}136 \text { by } 321 \\
136 \text { by } 318\end{array}$ \\
\hline 6 & $\begin{array}{l}\text { Brazil } \\
\text { vegetation }\end{array}$ & BRAZ & $\begin{array}{l}223 / 76 \\
-23^{\mathrm{d}},-52^{\mathrm{d}}\end{array}$ & $\begin{array}{l}937 \text { by } 389 \\
932 \text { by } 384\end{array}$ \\
\hline 7 & $\begin{array}{l}\text { Congo } \\
\text { vegetation }\end{array}$ & CONG & $\begin{array}{l}175 / 63 \\
-5^{\mathrm{d}},+26^{\mathrm{d}}\end{array}$ & $\begin{array}{l}427 \text { by } 293 \\
421 \text { by } 290\end{array}$ \\
\hline 8 & $\begin{array}{l}\text { Railroad } \\
\text { Valley Playa, } \\
\text { Nevada }\end{array}$ & RVPN & $\begin{array}{l}40 / 33 \\
+38^{\mathrm{d}} 29^{\mathrm{m}},-115^{\mathrm{d}} 40^{\mathrm{m}}\end{array}$ & $\begin{array}{l}71 \text { by } 29 \\
71 \text { by } 29\end{array}$ \\
\hline
\end{tabular}

L7 =Landsat-7 ETM+ and L5=Landsat-5 TM. Cell sizes are given in terms of number of pixels by number of lines $(30-\mathrm{m}$ resolution). WRS $=$ Worldwide Reference System.

equation that characterizes $\Delta Q_{i \mathrm{~L} 5 A}$ as a function of $\Delta Q_{i \mathrm{~L} 7}$. In particular,

$A_{i}=B_{i}\left(E_{0 i} \cos \theta\right)_{\mathrm{L} 7} /\left(E_{0 i} \cos \theta\right)_{\mathrm{L} 5}$,

where

$B_{i}=\rho_{i \mathrm{~L} 7}^{*} / \rho_{i \mathrm{~L} 5}^{*}$.

Even though the scene imaged by the two sensors is assumed to be unchanged, $\rho_{i \mathrm{~L} 5}^{*}$ and $\rho_{i \mathrm{~L} 7}^{*}$ are not the same because of the differences in relative spectral response profiles between corresponding (analogous) spectral bands and because of scene bi-directional reflectance effects due to differences in illumination and observation angles. In general, even if the same sites are imaged the same day by two satellite sensors, sun-angle and off-nadir viewing geometry differences can arise between acquisitions. In practice in the Landsat tandem configuration case, bi-directional reflectance effects are not expected to be significant since both Landsat sensors have nearnadir viewing geometry and the sun-angle difference between the tandem acquisitions is only $2-3^{\circ}$. Teillet et al. (2001a) found that spectral band difference effects can be significant, despite the close similarity in spectral filters and response functions between L7 and L5, and more dependent on the surface reflectance spectrum than on atmospheric and illumination conditions. In that study, a variety of terrestrial surfaces were assessed regarding their suitability for Landsat radiometric cross-calibration in the absence of surface reflectance spectra.

It follows from Eq. (5) that sensor L5 responsivity $G_{i \mathrm{~L} 5}$ in spectral band $i$ is given (in counts per unit radiance) by

$G_{i \mathrm{~L} 5}=M_{i} G_{i \mathrm{~L} 7}$.

Thus, nearly coincident (same-day) data acquisitions over common targets make it possible to use image data from the well-calibrated L7 to update the radiometric calibration of L5 in analogous spectral bands. One of the keys is to have sufficient knowledge of the factor $B_{i}$, since uncertainty in the crosscalibration is directly proportional to the uncertainty in $B_{i}$. However, for all but two of the tandem image pairs involved in this study, no information is available concerning the spectral character of the scenes. Thus, in order to explore the potential usefulness of the tandem scenes, it was necessary to set $B_{i}$ to

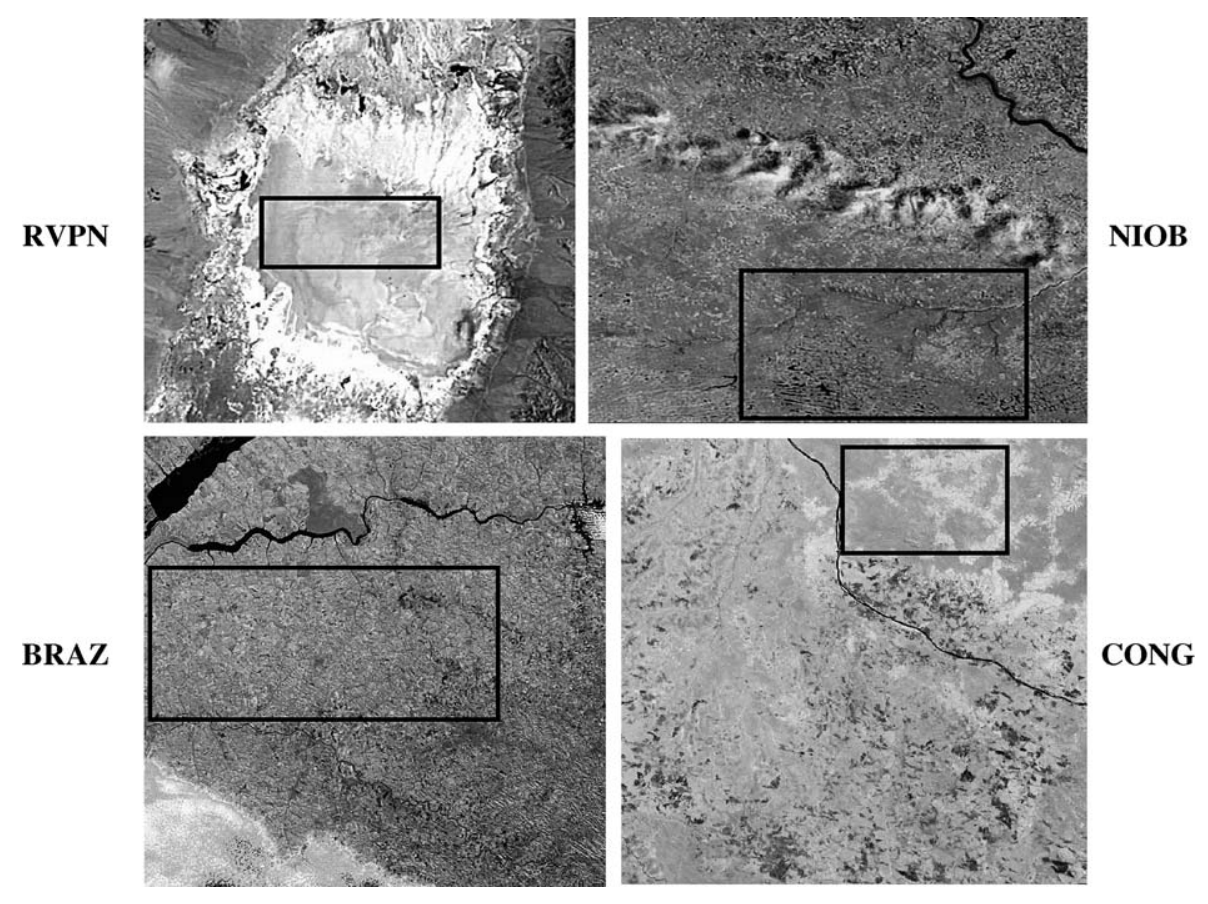

Fig. 1. Four of the tandem image pairs, where the rectangles outline the sub-scenes used in the analysis. The rectangles were subdivided into a grid of 5 by 5 cells in each case. Table 1 lists the cell sizes and the number of 30 -m pixels per grid cell. 
unity for the other six image pairs. In spectral bands $1-5$ and 7 , the $B_{i}$ values for RVPN are $0.981,0.981,0.994,1.003,1.026$, and 0.954 , respectively. The $B_{i}$ values for NIOB are 1.020 , $1.022,0.977,1.014,1.039$, and 0.932 .

\subsection{Image processing and analysis}

The standard image processing and statistical analysis steps described by Teillet et al. (2001a) were used again to obtain the $M_{i}$ slopes in Eq. (5) for use in Eq. (8). The $\Delta Q_{i \mathrm{~L} 5 A}$ and $\Delta Q_{i \mathrm{~L} 7}$ for use in Eq. (5) were obtained from large sub-scene areas in common between L7 ETM+ and L5 TM data pairs. For each pair, a 5 by 5 grid of contiguous image windows or cells were set up and $\Delta Q_{i}$ means and standard deviations extracted from each of the 25 grid cells. This grid-cell image-block approach was used for the common ground-look areas to facilitate geometric registration and group lots of pixels (Table 1). Sub-pixel geometric registration is not critical in this approach, but care was taken to capture the common area as accurately as possible. Note that an area common to the two images in a pair can have slightly different numbers of lines and pixels because of differences in L7 and L5 satellite altitude and sensor scanning times.

After preprocessing in accordance with the radiometric formulation described in the previous section, sub-scene gridcell means for $\Delta Q_{i \mathrm{~L} 5 A}$ and $\Delta Q_{i \mathrm{~L} 7}$ from all eight tandem image pairs were plotted to obtain the slopes $M_{i}$ (Eq. (5)) for each spectral band $i$. Because the quantized levels are biassubtracted, the linear fits were forced to have zero intercepts. The plot for each band included 200 points ( 25 cells times 8 image pairs).

\section{Results}

\subsection{Image cross-comparisons}

The $M_{i}$ slopes derived from the eight image pairs combined (Fig. 2) are listed in Table 2. The zero-intercept linear fits yield

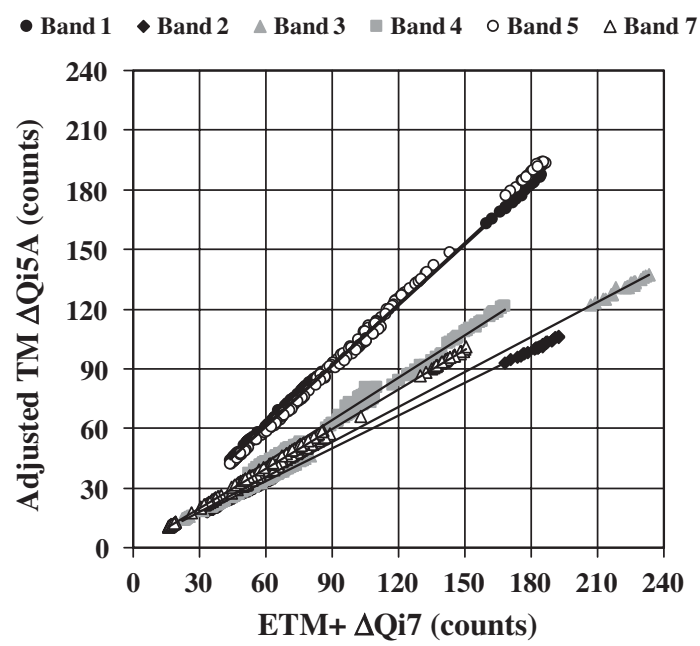

Fig. 2. Plot of grid-cell $\Delta Q_{i \mathrm{~L} 5 A}$ and $\Delta Q_{i \mathrm{~L} 7}$ means combined for the eight tandem image sub-scene pairs. The lines are linear fits (Table 1) with forced zero intercepts.
Table 2

Upper table: Linear fit results corresponding to the plots shown in Fig. 2, where $X=\Delta Q_{i \mathrm{~L} 7}$ and $Y=\Delta Q_{i \mathrm{~L} 5 A}$

\begin{tabular}{|c|c|c|c|c|c|}
\hline Band $i$ & $\begin{array}{l}\text { Fit } \\
\text { equation } \\
Y=M_{i} X\end{array}$ & $\begin{array}{l}\text { Uncertainty } \\
\text { in } M_{i}\end{array}$ & $\begin{array}{l}\text { L5 gain } \\
\text { from ALL } \\
\text { pairs }\end{array}$ & $\begin{array}{l}\text { L5 gain from } \\
\text { L RVPN only }\end{array}$ & $\begin{array}{l}\text { \% difference } \\
\text { ALL vs. } \\
\text { RVPN }\end{array}$ \\
\hline 1 & $Y=1.0158 X$ & 0.0079 & 1.244 & 1.242 & $0.18 \%$ \\
\hline 2 & $Y=0.5529 X$ & 0.0041 & 0.6585 & 0.6561 & $0.36 \%$ \\
\hline 3 & $Y=0.5873 X$ & 0.0058 & 0.9033 & 0.9050 & $-0.18 \%$ \\
\hline 4 & $Y=0.7125 X$ & 0.016 & 1.066 & 1.082 & $-1.5 \%$ \\
\hline 5 & $Y=1.0244 X$ & 0.055 & 8.034 & 8.211 & $-2.2 \%$ \\
\hline 7 & $Y=0.6631 X$ & 0.013 & 14.63 & 14.70 & $-0.48 \%$ \\
\hline $\begin{array}{l}\text { Band } \\
i\end{array}$ & $\begin{array}{l}\text { Fit equation } \\
Y=M_{i} X+I_{i}\end{array}$ & \multicolumn{2}{|c|}{$\begin{array}{l}\text { L5 gain from } \\
\text { ALL pairs, } \\
\text { non-zero } \\
\text { intercept }\end{array}$} & $\begin{array}{l}\text { L5 gain from } \\
\text { ALL pairs, } \\
\text { zero intercept }\end{array}$ & $\begin{array}{l}\% \text { difference } \\
\text { non-zero vs. } \\
\text { zero intercept }\end{array}$ \\
\hline 1 & $\begin{array}{l}Y=1.0169 X \\
-0.1087\end{array}$ & 1.246 & \multicolumn{2}{|r|}{1.244} & $0.11 \%$ \\
\hline 2 & $\begin{array}{l}Y=0.5508 X \\
+0.2124\end{array}$ & 0.6560 & \multicolumn{2}{|r|}{0.6585} & $-0.38 \%$ \\
\hline 3 & $\begin{array}{l}Y=0.5867 X \\
+0.0835\end{array}$ & 0.9023 & \multicolumn{2}{|r|}{0.9033} & $-0.10 \%$ \\
\hline 4 & $\begin{array}{l}Y=0.7316 X \\
-2.1553\end{array}$ & 1.095 & \multicolumn{2}{|r|}{1.066} & $2.7 \%$ \\
\hline 5 & $\begin{array}{l}Y=1.0846 X \\
-6.9793\end{array}$ & 8.506 & \multicolumn{2}{|r|}{8.034} & $5.9 \%$ \\
\hline 7 & $\begin{array}{l}Y=0.6671 X \\
-0.3515\end{array}$ & 14.72 & \multicolumn{2}{|c|}{14.63} & $-0.62 \%$ \\
\hline
\end{tabular}

Lower table: Comparison of linear fit results with and without a forced zero intercept, where the non-zero intercept for band $i$ is $I_{i}$.

very good coefficients of determination ( $R$-squared) in all six spectral bands. The $R$-squared values and the dynamic range covered in the plot clearly indicate the benefit of combining darker and brighter sites for radiometric cross-calibration. Table 2 compares the L5 gain results based on eight tandem image pairs to those based on RVPN only. Given that the fits are forced to go through the origin and that RVPN is the brightest site, one would expect reasonably close results. They are within $\pm 0.5 \%$ for bands $1-3$ and 7 and within $-2.2 \%$ for bands 4 and 5 . Table 2 also provides linear fit results obtained without the forced zero intercept constraint. Spectral bands 1, 2, 3, and 7 have small intercepts (a few tenths of a count), but bands 4 and 5 have intercepts of 2.2 and 7.0 counts, respectively. These nonnegligible intercepts are generally consistent with the distribution of residuals in bands 4 and 5 described in the next paragraph. In all spectral bands, the unaccounted for variances in percent, $100\left(1-R^{2}\right)$ (not shown), remain low without the forced zero intercepts.

The residuals plotted in Fig. 3 indicate that some of the tandem data sets do not blend well with the others, the CONG, BRAZ and ESLM data sets being the biggest outliers. Insufficient information is available to determine if residuals in the various bands are mainly due to spectral band difference effects, but they could be in principle given the diversity of the scenes involved, the majority of which are vegetated. No explanation has been found for the notable scatter in spectral band 4 for the NIOB data set (the surface reflectance spectrum exhibits normal behaviour). 

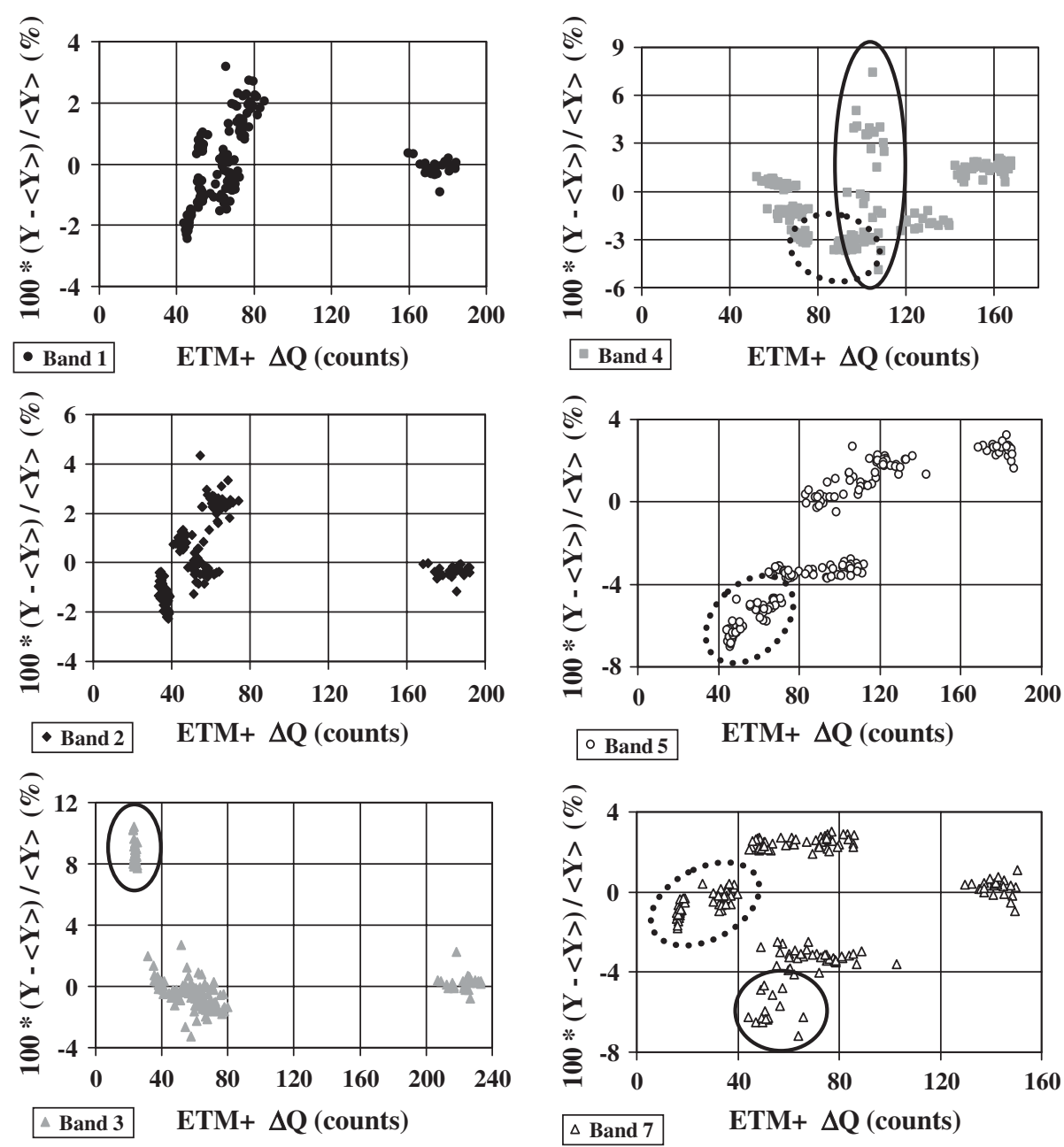

Fig. 3. Residuals between $Y=\Delta Q_{i \mathrm{~L} 5 A}$ and $\langle Y>$ from the linear fit equations (this figure and Table 1) as a function of ETM $+\Delta Q$. The encircled band 3 points are from the CONG tandem pair. The band 4 points within the solid-line circle are from the NIOB tandem pair. The band 7 points within the solid-line circle are from the ESLM tandem pair. Points within the dotted-line circles are from the two vegetated locations where humid atmospheric conditions prevail in June (CONG and BRAZ).

In band 5, spectral bandpass differences between L7 and L5 are large enough to respond differently to atmospheric water vapour absorption. This could be a significant factor for some of the sites given their locations. This point is illustrated in Fig. 4, which plots the band 5 relative spectral response profiles for L7 and L5 as well as gas transmittances in the same bands for tropical and US62 standard atmospheric models with columnar water vapour contents of 4.12 and $1.424 \mathrm{~g} / \mathrm{cm}^{2}$, respectively. To examine this possibility further, L7 and L5 at-sensor reflectances were simulated using the Canadian Advanced Modified 5S (CAM5S) code (O'Neill et al., 1996) for the tropical and US62 models. Other CAM5S inputs consisted of a vegetation surface reflectance spectrum, a continental aerosol model, an aerosol optical depth of 0.05 at $0.55 \mu \mathrm{m}$, and a solar zenith angle of $60^{\circ}$. Sea-level terrain elevation, an Earth-Sun distance of 1 A.U., and nadir viewing geometry were also assumed. The ratio of simulated L7 and L5 at-sensor reflectances was used to obtain $B_{i}$ (Eq. (7)) and the resulting $B_{i}$ values were then compared for the tropical and US62 model runs. (Recall that uncertainty in the cross-calibration is directly proportional to the uncertainty in $B_{i}$ ). For spectral bands 1-3, the differences between $B_{i}$ results for the tropical and US62 runs are less than $0.3 \%$. The differences for spectral bands 4,5 and 7 are $+1.0 \%$, $+2.4 \%$ and $-1.6 \%$, respectively. These differences are reasonably consistent with the direction of residuals in these bands in Fig. 3 (which are based on unity $B_{i}$ computations) for the two vegetated locations where humid atmospheric conditions prevail in June (CONG and BRAZ), bearing in mind that spectral band differences due to surface cover type are not taken into account.

Thus, when multiple locations are used for cross-calibration, lack of knowledge about atmospheric water vapour content can potentially affect results significantly in the longer wavelength bands, especially in Landsat band 5. For the purposes of crosscalibration without field measurements, it would be worthwhile obtaining ancillary data on atmospheric water vapour content from meteorological services if at all possible. Results from additional CAM5S runs for different input parameters (not presented) indicate that differences between tropical and US62 cases as a function of surface type and aerosol optical depth are very small (fractions of a percent relative) and as a function of solar zenith angle are small (10\% to $20 \%$ relative). 


\subsection{Cross-calibration gain comparisons}

The main interest in this study was to assess the relative merits of using additional tandem image pairs as opposed to improving the absolute results already obtained for the L5 TM gain coefficients obtained from the use of Eq. (8) for RVPN alone. Therefore, a plot was generated to look at the percent differences between L5 gain estimates based on an increasing number of tandem pairs and the estimate based on RVPN only as the reference case (Fig. 5). A given sub-set of tandem pairs includes all tandem pairs listed in Table 1 up to and including that "Pair \#". Although the distribution of the results in Fig. 5 depends on the order in which the tandem pairs are added, it is doubtful that more would be learned by looking at different sequences in this regard. Apart from bands 4 and 5, the addition of seven tandem pairs yields results generally within approximately $\pm 1 \%$ of the RVPN-based gain without surface reflectance spectra for the additional sites (except NIOB, which had a surface reflectance spectrum available). Differences for spectral band 4 get increasingly larger with an increasing number of tandem pairs, reaching approximately $-2 \%$. Differences for spectral band 5 get increasingly larger with an increasing number of tandem pairs, approaching $-4 \%$. This is consistent with the sites that have the greatest residuals in band 5 (Fig. 3), which are pair numbers $4-7$ in Table 1 (BOTS, AUST, BRAZ, and CONG). Differences for spectral band 7 are in the $4 \%$ range for the first three pair cases, but decrease to the $1 \%$ range with additional pairs.

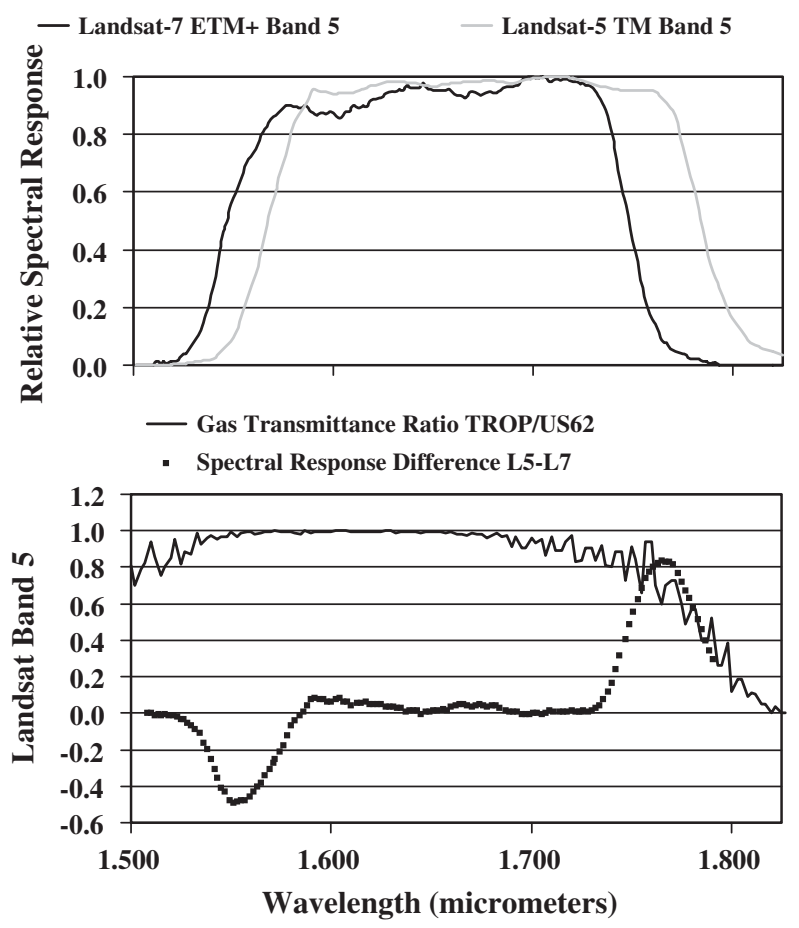

Fig. 4. The upper graph plots the relative spectral response profiles for the Landsat-5 (L5) and Landsat-7 (L7) band 5 analogues. The difference between the two spectral band profiles is plotted in the lower graph. The lower graph also plots the ratio of atmospheric gas transmittances for the tropical (TROP) and US62 models.

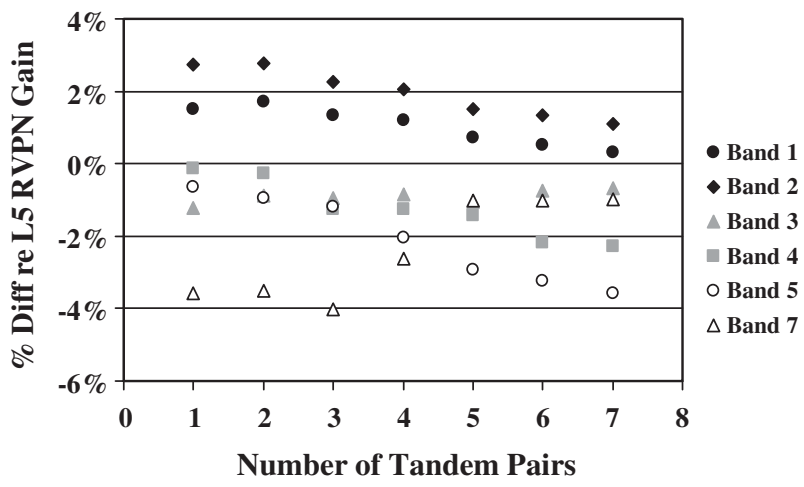

Fig. 5. Percentage differences between Landsat-5 TM gain estimates based on the indicated number of tandem pairs and the estimate based on RVPN only as the reference case.

Using the grid-cell image-block approach for the common ground-look area (which facilitates geometric registration and groups lots of pixels) was appropriate for the RVPN-based L7-L5 cross-calibration to update Landsat 5 TM gain coefficients because RVPN is a reasonably uniform target spectrally and a surface reflectance spectrum was available. The new results for additional tandem image pairs suggest that the grid-cell image-block approach is a reasonable one for tandem image pairs of primarily vegetated areas for which surface reflectance spectra are not available for use in radiometric crosscalibration analysis. The alternative methodology of generating and subsequently blending cross-calibration results based on specific isolated targets with individual (known or unknown) reflectance spectra has not been tried. The results from this investigation suggest that pursuing such an alternative methodology would only be worthwhile if surface reflectance spectra are known.

\section{Concluding remarks}

Increasing the number of Landsat-7-Landsat-5 tandem pairs yielded cross-calibration results for Landsat 5 TM gain coefficients in spectral bands $1,2,3$ and 7 within approximately $\pm 1 \%$ of the RVPN-based results. Results for spectral bands 4 and 5 are within $-2 \%$ and $-4 \%$ of the RVPNbased results, respectively. Thus, for Landsat, it is reasonable to use the combination of multiple near-simultaneous ground looks as a supplementary check on radiometric calibration even without coincident surface measurements. Moreover, the new results presented in this paper suggest that the grid-cell image-block approach originally adopted for the Landsat cross-calibration is a reasonable approach for tandem image pairs of primarily vegetated areas for which surface reflectance spectra are not available for use in the radiometric crosscalibration analysis.

Nevertheless, it was found that some of the tandem data sets do not blend well with the others. It is possible but not proven that at least part of the residual differences is attributable to spectral band difference effects. In addition, simulations of atsensor reflectance indicate that lack of knowledge about atmospheric water vapour content on the days of near-simultaneous 
image acquisition can, potentially, affect Landsat crosscalibration in spectral bands 4,5 and 7 .

\section{Acknowledgements}

The authors thank Gunar Fedosejevs, Jim Storey, John Barker, Alexander Chichagov and Leander Campbell for helpful discussions and technical assistance. The authors also appreciate the efforts of the anonymous reviewers who pointed out several aspects of the paper that required clarification. The support of the Land Cover Satellite Project Science Office (NASA Goddard Space Flight Center, Greenbelt, Maryland) for portions of this work is gratefully acknowledged.

\section{References}

Cabot, F., Hagolle, O., \& Henry, P. (2000). Relative and multi-temporal calibration of AVHRR, SeaWiFS, and Vegetation using POLDER characterization of desert sites. Proceedings of the International Geoscience and Remote Sensing Symposium (IGARSS), 5, 2188-2190.

O'Brien, D. M., \& Mitchell, R. M. (2001). An error budget for cross-calibration of AVHRR shortwave channels against ATSR-2. Remote Sensing of Environment, 75, 216-229.

O'Neill, N.T., Royer, A., \& Nguyen, M.N. (1996). Scientific and technical report on the development of a modified version of the H5S Code which incorporates major features of the 6S Code. Internal report CARTEL-1996020, CARTEL, Department de géographie et télédétection, 2500, boul. de
l'Université, Université de Sherbrooke, Sherbrooke, Québec, Canada J1K 2R1, $62 \mathrm{p}$.

Rao, C. R. N., Cao, C., \& Zhang, N. (2003). Inter-calibration of the moderateresolution imaging spectroradiometer and the along-track scanning radiometer-2. International Journal of Remote Sensing, 24(9), 1913-1924.

Teillet, P. M., Barker, J., Markham, B. L., Irish, R. R., Fedosejevs, G., \& Storey, J. C. (2001a). Radiometric cross-calibration of the Landsat-7 ETM+ and Landsat-5 TM sensors based on tandem data sets. Remote Sensing of Environment, 78, 39-54.

Teillet, P. M., Fedosejevs, G., Gauthier, R. P., O’Neill, N. T., Thome, K. J., Biggar, S. F., et al. (2001b). A generalized approach to the vicarious calibration of multiple earth observation sensors using hyperspectral data. Remote Sensing of Environment, 77(3), 304-327.

Teillet, P. M., Helder, D. L., Ruggles, T. A., Landry, R., Ahern, F. J., Higgs, N. J., et al. (2004a). A definitive calibration record for the Landsat-5 thematic mapper anchored to the Landsat-7 radiometric scale. Canadian Journal of Remote Sensing, 30(4), 631-643.

Teillet, P. M., Slater, P. N., Ding, Y., Santer, R. P., Jackson, R. D., \& Moran, M. S. (1990). Three methods for the absolute calibration of the NOAA AVHRR sensors in-flight. Remote Sensing of Environment, 31, 105-120.

Thome, K. J., Biggar, S. F., \& Wisniewski, W. (2003). Cross comparison of EO-1 sensors and other earth resources sensors to Landsat-7 ETM+ using Railroad Valley Playa. IEEE Transactions on Geoscience and Remote Sensing, 41, 1180-1188.

Trishchenko, A. P., Cihlar, J., \& Li, Z. (2002). Effects of spectral response function on surface reflectance and NDVI measured with moderate resolution satellite sensors. Remote Sensing of Environment, 81(1), 1-18. 